\title{
Heraldos de cine: imágenes del cine y la construcción estética del colombiano moderno
}

\author{
Heralds of cinema: Images of the cinema and the aesthetic \\ construction of the modern Colombian
}

Claudia Angélica Reyes Sarmiento Magíster en Estética e Historia del Arte Universidad Jorge Tadeo Lozano Correo electrónico: claudiaa.reyes@utadeo.edu.co

Artículo de investigación DOI: http://dx.doi.org/10.15332/s2339-3688.2016.0002.02

Fecha de recepción: febrero 21 de 2016 • Fecha de aprobación: junio 29 de 2016

\section{RESUMEN}

Este texto es el resultado de un proceso de investigación adelantado en el grupo de estudios de la Imagen, adscrito a la Facultad de Artes y Diseńo de la Universidad Jorge Tadeo Lozano (Colombia), en él se analiza el concepto de ciudad y su relación con la construcción de lo que significó ser modernos en Bogotá, a partir del ingreso de películas norteamericanas en los años treinta, cuando grandes productoras de cine ejercieron una gran influencia sobre el mercado latinoamericano. Dicho análisis partirá de aspectos como la introducción del Starsystem, el concepto de ser modernos, del proceso de modernización en Colombia, los heraldos de cine y el análisis de los discursos visuales.

Palabras clave: cine norteamericano, sistema de estrellas, heraldos, carteles, imagen. 


\begin{abstract}
This text is the result of a research process produced in the group of studies of the Image affiliated to Universidad Jorge Tadeo Lozano (Colombia). It analyses the concept of the city and its relationship with the construction of what it meant to be modern in Bogotá, Colombia, since the entrance of American Cinema in the Nineteen-thirties, when a great deal of film producers exerted a great influence on the Latin American market. This analysis starts with aspects such as the introduction of the Star-system; the concept of being modern and the process of modernization in Colombia, the heralds of cinema, and the analysis of visual discourses.
\end{abstract}

Keywords: American cinema, star system, heralds, posters, image.

\title{
INTRODUCCIÓN
}

Para comenzar, debe hacerse una indagación sobre el concepto de ciudad ${ }^{1}$, en el cual intervienen dos elementos: las narraciones sobre la ciudad y la imagen de la ciudad. Cuando se mezclan dichos componentes, una persona puede referirse a una ciudad como bonita, violenta, agradable, desagradable, etc.; también, va estableciendo imaginarios urbanos. Este es el caso de la construcción del concepto de ciudad en Bogotá, a partir de la llegada del cine.

El cine ha contribuido a la construcción de mitos urbanos al consolidar la idea de ciudad como imagen y como mito: "las imágenes provenientes de la literatura, del cine y la televisión, de los periódicos forman, en torno a nosotros, otra ciudad, la ciudad narrada” (Silva, 2004, p. 58).

1 De acuerdo con Louis Wirth (2005): "el dominio de la ciudad, especialmente de la gran ciudad, puede ser visto como una consecuencia de la concentración operada en ella de servicios y actividades industriales, comerciales, financieros y administrativos; de líneas de transporte y comunicación; de equipos culturales y recreativos tales como la prensa, estaciones de radio, teatros, bibliotecas, museos, salas de conciertos, teatros líricos, hospitales, instituciones de educación superior, centros de investigaciones, publicidad, organizaciones profesionales e instituciones religiosas y de beneficencia”. 
Estas narraciones permiten construir otras ideas alrededor de lo que es la ciudad o trasladar patrones culturales establecidos en otros contextos a entornos diferentes. Es así como los conceptos de ciudad europea o norteamericana fueron trasladados a la Bogotá de los años treinta, cuarenta y cincuenta, a través de ciertos estereotipos que se manifiestan no solo en la idea de ciudad como elemento material, sino en los sujetos que la habitan, en aquellos que se empezaron a llamar ciudadanos y cuya denominación se articuló con las diferentes ideas sobre lo que significaba ser moderno, y es desde esa mirada sobre los sujetos y los modos de ser, sobre los cuales se puede hablar de la configuración de imaginarios urbanos, sin que estos correspondan al contexto bogotano y a la situación real de la ciudad. Sin embargo, a partir del traslado de dichos estereotipos, se observa la aparición de la idea de ciudad imaginada y ciudad deseada (términos empleados por Armando Silva) del sistema de estrellas (Star-system) norteamericano. Para empezar, es necesario conocer acerca de los orígenes del cine colombiano y del contexto histórico de Bogotá entre 1930 y 1940.

La historia del cine colombiano se inicia con los hermanos Di Doménico, sus películas eran construidas bajo los principios del cine mudo, lo cual era favorable para la parte de producción. Esos primeros filmes trataban, especialmente, temas basados en la cotidianidad.

Durante la década de los veinte, el cine colombiano adquiere un carácter costumbrista y aparecen películas como María, basada en la novela de Jorge Isaacs, y Aura o las violetas, producida y dirigida por los hermanos Di Doménico. Posteriormente, surgen los hermanos Acevedo, quienes producen películas como La tragedia del silencio y Bajo el cielo antioqueño, esta última considerada como una de las mejores cintas producidas por el cine colombiano de aquellos años.

Hasta ese momento, se puede hablar de producciones nacionales construidas a partir de patrones socioculturales propios, cargados de una fuerte tendencia costumbrista, donde las imágenes reflejaban las tradiciones y los roles típicos del pueblo colombiano de la época (figuras 1 y 2). De esta manera, el cine colombiano contribuyó al fortalecimiento de la idea de Nación, concepto que se reflejó en algunos temas abordados en las películas como Bajo el cielo antioqueño (1925) y Alma provinciana (1926) en las que se manifiesta la sociedad colombiana de la década del veinte. 
Campos en Ciencias Sociales

Discursos visuales y sociedad
Figura 1. Película Garras de oro

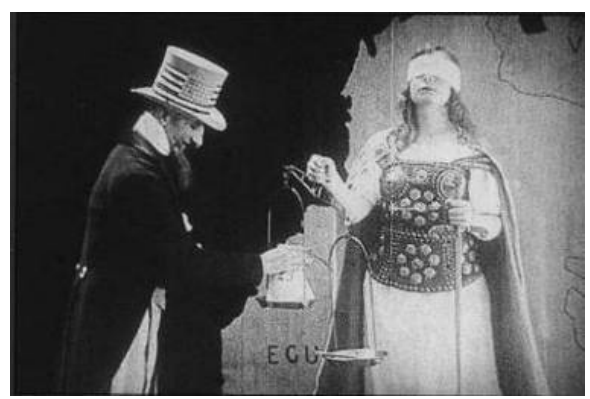

Fuente: Fundación Patrimonio Fílmico Colombiano (1926)

Figura 2. Bajo el cielo Antioqueño

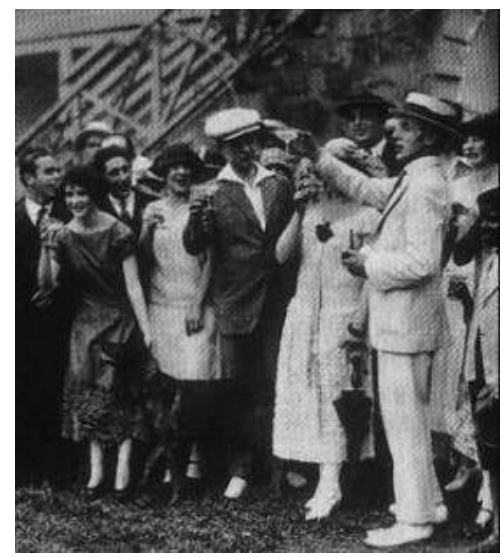

Fuente: Fundación Patrimonio Fílmico Colombiano (1925)

A finales de los años veinte, aparece el cine sonoro y, al mismo tiempo, se crea Cine Colombia, institución que inicialmente tenía el objetivo de fortalecer la producción de cine nacional, pero finalmente terminó apoyando la entrada de películas extranjeras, lo cual debilitó la industria nacional y la idea de "nosotros", que se había reflejado en la etapa anterior. 
Posteriormente, en la década de los treinta, las políticas culturales de Olaya Herrera, presidente liberal, pretendieron mejorar las condiciones del cine colombiano, no obstante, este va a ser un periodo de parálisis en la producción nacional, como se explica a continuación.

La década de los años treinta en Colombia se caracterizó por un desarrollo marcado en diferentes ámbitos, el cual fue impulsado por las políticas del liberalismo colombiano que, por aquellos años, ostentaba el poder. Políticas como la nombrada por Silva (2004):

Una extensión y democratización de la cultura, bajo el supuesto de que para lograrlo era necesario acudir a todas las formas modernas de comunicación de la cultura y de la técnica (el impreso y el libro, pero también el cine, la radio y las conferencias culturales). (p. 89)

Lo anterior permitió tener acceso, entre otros, al cine extranjero, particularmente el estadounidense.

Si bien las políticas adoptadas dieron lugar a ciertas transformaciones en la sociedad colombiana, resulta evidente que las condiciones económicas, sociales y culturales de Estados Unidos distaban de la realidad nacional; sin embargo, esas diferencias no impidieron que el cine norteamericano, con sus películas y sus estrategias de propaganda, introdujera al país nuevos patrones culturales a través del uso de la imagen.

Durante la década de los cuarenta, el presidente Eduardo Santos continuó con un marcado interés por el fortalecimiento de la cultura. De esta manera, crea un proyecto de extensión cultural y bellas artes que incluía la ampliación del sistema educativo: primaria, secundaria, industrial y normal; además, gestiona espacios para una sección de cinematografía, museos de arqueología, la publicación de la Revista de Indias, la Banda Nacional de Bogotá, la Radiodifusora Nacional de Bogotá, escuelas ambulantes, diferentes ferias del libro y conferencias culturales, cursos de educación física, patronatos escolares y centros de cultura social, construcción de planteles educativos y ayudas, en forma de becas y pensiones, a estudiantes de bajos recursos 
(Mora y Carrillo, 2003). Estos proyectos contribuyeron a que se fortaleciera el mito de Bogotá como Atenas Suramericana.

En cuanto a la sociedad bogotana, las clases media y alta estaban inclinadas a construir una imagen propia que correspondiera con aquella de las clases altas europeas o norteamericanas, hecho que contrastaba con la realidad de otros sectores de la sociedad. De tal modo que en un mismo espacio se percibía una ciudad con rasgos europeos y otra ciudad que reflejaba una imagen más cruda de la realidad. En esa forma de concebir la ciudad y de crear un mito a partir de ella, participaron con gran fuerza medios masivos de comunicación como el cine.

En el caso de Bogotá, en la década de los años treinta, se nota la influencia marcada del sistema de estrellas (Star-system), un fenómeno publicitario, o de las estrellas, a través del cual se exaltó la figura de los actores y las actrices, los cuales dejaron de ser tan solo los personajes en una película para ser elevados al nivel de mitos².

Esta mitificación se daba a partir de la caracterización de la imagen de los personajes que aparecían en las películas, en las cuales, además, se trataban temas que determinaban roles masculinos o femeninos muy marcados, como por ejemplo, el de la mujer supeditada a la figura masculina, además de otros estereotipos.

2 "El Mito, desde el uso obtenido en las primitivas formas de organización social, hasta el concepto que hoy adquiere en los sistemas económicos industrializados, es un mensaje y como tal inscrito dentro de un sistema de comunicación. Los lenguajes, en las diferentes formas de expresión, poseen mecanismos mitificadores que permanentemente deben estarse abocando para superar la neutralización y modificación del contenido del acto comunicador.

La mitificación del mensaje obedece a razones implícitas de los lenguajes y por ello se puede afirmar que lo que normalmente entendemos por comunicarnos es, ante todo, una permanente transmisión de mitos, pues al estar estos colocados en el nivel superestructural de la realidad y siendo ellos sustento de los valores sobre los cuales se mantiene una organización política, los procesos (incluyendo arte y medios) de comunicación actúan a través de una realidad "defendida", "aparentada" y la organización de sus contenidos pasa ya por esos rigurosos filtros, creando el sistema de comunicación que les es particular” (Silva, 1978, pp. 60-61). 
Figura 3. Película Delicious

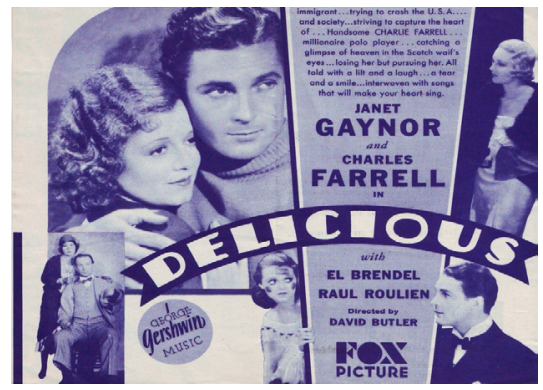

Fuente: Fundación Patrimonio Fílmico Colombiano

Figura 4. Película Deliciosa

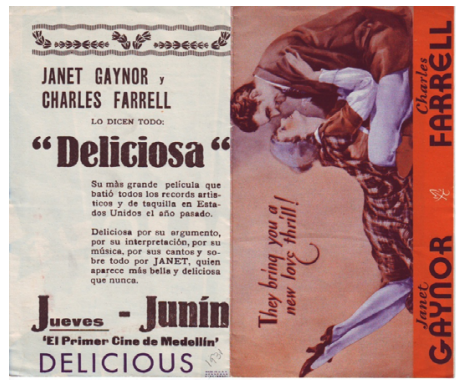

Fuente: Fundación Patrimonio Fílmico Colombiano

Este proceso de mitificación, se produce a través de la relación entre los productores de la imagen, el objeto o imagen fotográfica y el receptor, a partir de unos registros visuales que denotan, en un nivel, un sentido obvio, y que connotan, en otro nivel, un sentido obtuso.

Como lo presenta Barthes (1999), el rostro de Greta Garbo, una de las imágenes que ha sido mitificada a través de las estrategias del sistema de estrellas (Star-system), es un rostro que se convierte en el ideal de cualquier mujer para su época. 
Campos en Ciencias Sociales

Discursos visuales y sociedad

En las imágenes de Garbo, se evidencia el concepto de rostro-objeto (Barthes, 1999, p. 42), construido por un sistema, objeto que personifica ideales, deseos y estereotipos: "la imagen individual de la estrella -evidentemente un miembro individual de la sociedad- ofrece un foco adecuado para una serie de temas que reverberan en la sociedad como conjunto: éxito, riqueza, amor, comportamiento social aceptable y consumo, entre otros" (Allen y Gomery, 1995, p. 225) (figuras 5, 6 y 7).

Figura 5. Película Daddy Long Legs

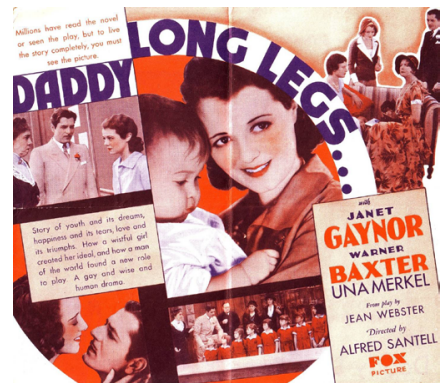

Fuente: Fundación Patrimonio Fílmico Colombiano

Figura 6. Película Man of the forest

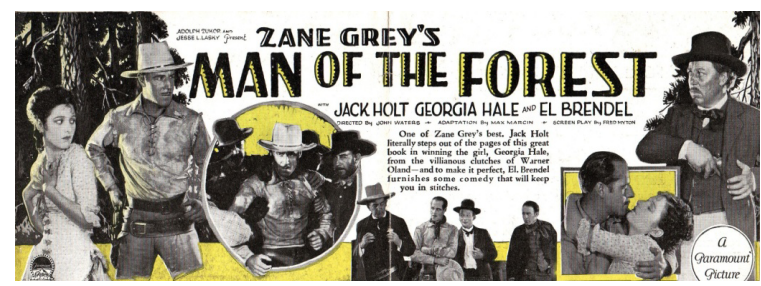

Fuente: Fundación Patrimonio Fílmico Colombiano 
Figura 7. Película Broadway Bad

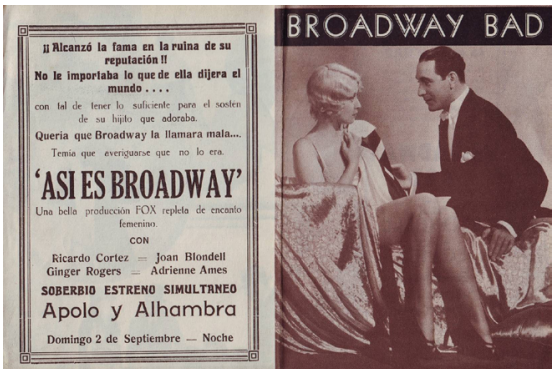

Fuente: Fundación Patrimonio Fílmico Colombiano

Una evidencia del traspaso de esa imagen mitificada son algunos avisos publicitarios en Colombia que hicieron uso de esos rostros objeto para la promoción de otros productos. En la figura 8 se observa un cartel que promociona, en Bogotá, pastillas para el aliento llamadas Millefleurs. En dicha pieza gráfica se recurre a la imagen de Garbo (rostro-objeto) para construir el registro visual y se refuerza con un texto, registro verbal, en el que se lee: "Greta Garbo dice: fragancia de violetas en besos de mujer encontrará usted en las pastillas Millefleurs". Ambos elementos (registro visual y registro verbal) hacen parte de aquellos que llevan a la interpretación de otros sentidos, mediados por unos códigos (culturales, cinematográficos, retóricos, etc.), que nos hablan de un estereotipo femenino.

Figura 8. Anuncio Millefleurs

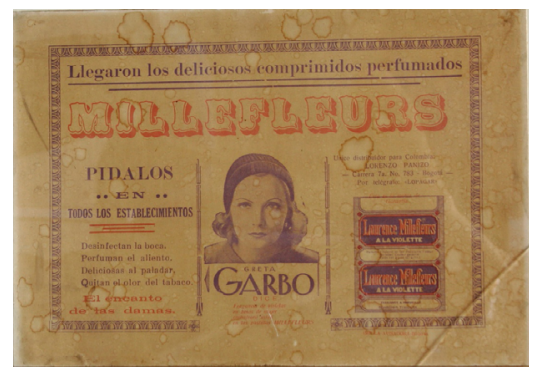

Fuente: Fundación Patrimonio Fílmico Colombiano 
Campos en Ciencias Sociales

Discursos visuales y sociedad

Ese proceso de mitificación depende, además, de la relación entre producción y recepción del mensaje que estuvo supeditada a las necesidades económicas de una industria específica en una época donde había crisis y cuyos receptores eran universales, es decir, no solo norteamericanos, o de habla inglesa, sino sociedades completamente diferentes, como las latinoamericanas.

Para dicho proceso de mitificación se recurría a estrategias publicitarias en las que se empleaban diferentes formas de difusión. Una de esas formas es el cartel $^{3}$. Sin embargo, en la década de los treinta, las productoras de cine enviaban junto a la película otras piezas promocionales que apoyaban, en primer lugar, el contenido de la película y, además, el contenido de los carteles. Estos eran los heraldos de cine, también conocidos como programas de mano.

Figura 9. Película The Maltese Falcon

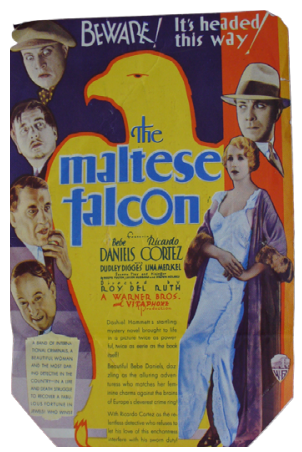

Figura 10. Película The Maltese Falcon

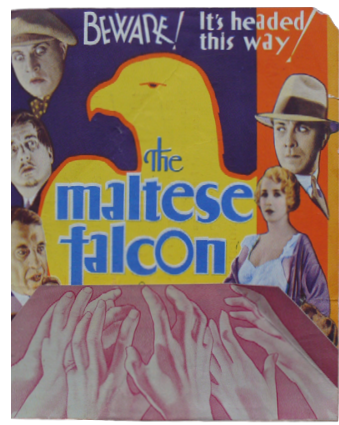

Fuente: Fundación Patrimonio Fílmico Colombiano. Década de los treinta

3 El cartel de cine como manifestación gráfica que promueve un producto de "consumo masivo", es a su vez reflejo de las condiciones de una sociedad, su pensamiento, su economía y su política, entre otros aspectos; es un espejo de dicha sociedad, como lo manifiesta Diego Coronado e Hijón (2001): "si hemos dicho anteriormente que el papel del emisor del cartel (y en general de toda la publicidad) tiende a difuminarse en el interior de la imagen en beneficio del papel del receptor, ahora debemos responder a la nueva relación que se derivará de esta otra situación comunicativa. Situación, en la que los elementos en juego aislados son los de una mirada (la del consumidor) y una imagen (la del producto o mensaje de publicidad)". 
Su origen se encuentra en los programas utilizados en las obras de teatro y ópera, y su propósito era ennoblecer el carácter popular del cine $e^{4}$. Las obras de teatro estaban acompañadas de programas de mano que cumplían con una función informativa: dar a conocer a los espectadores el nombre de los actores y demás participantes de la obra. Paulatinamente, esos programas, dadas sus características gráficas, se convirtieron en un objeto de colección.

Los formatos de los heraldos son variados, aunque generalmente sus medidas son 15 x 9 y 13.5 x $8 \mathrm{~cm}$. Algunos eran verticales, otros horizontales, unos de dos a cuatro cuerpos y algunos troquelados.

Figura 11. Película The Maltese Falcon

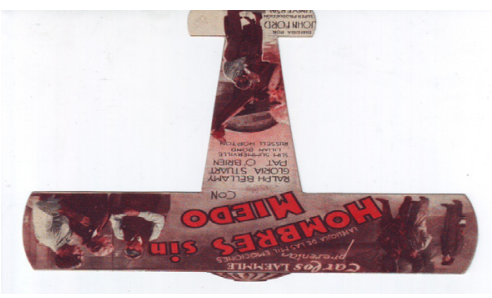

Figura 12. Película The Maltese Falcon

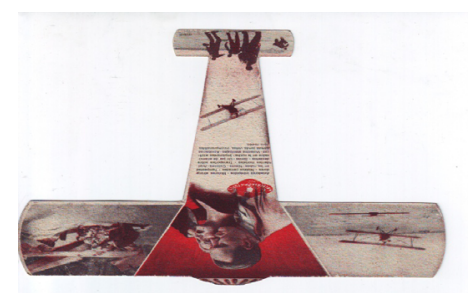

Fuente: Fundación Patrimonio Fílmico Colombiano

En la cara principal de los heraldos aparecen imágenes relacionadas con la película, generalmente se seleccionaban las escenas más representativas o llamativas. Esa cara del heraldo era la más trabajada. Allí también figuran el título de la película, el nombre de los actores protagonistas y, algunas veces, de los coprotagonistas; además, se relaciona el nombre de la productora de la película, bien sea la MetroGoldwyn-Mayer, Fox, Universal o Paramount Pictures y, en algunos casos, el de la distribuidora.

4 "Físicamente consistía en una pieza impresa sobre cartón delgado, compuesta por dos caras tiro-retiro (caradorso), sobre las cuales se imprimía una reproducción a escala del cartel original en policromía. Para los textos, en la mayoría de los casos, se hacía una selección del elemento clave de la descripción de la película. Estos funcionaban como una síntesis de la película al manejar dicho contenido en dos niveles: uno gráfico y otro textual”. (Duque, Reyes, Greiff, Peters y Almanza, 2009). 


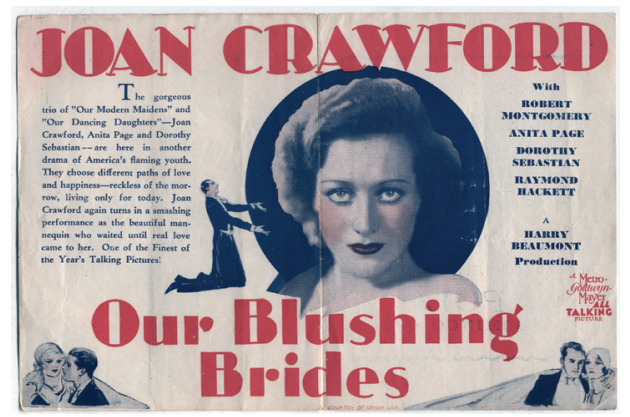

Fuente: Fundación Patrimonio Fílmico Colombiano

Por otro lado, en la contraportada se encuentran datos sobre el lugar donde sería proyectada la película, el día y la hora, entre otros. En el interior del programa nuevamente se juega gráficamente con las imágenes de los protagonistas en una escena reconocida de la película. En general, el diseńo producido por Hollywood fue bastante llamativo y las composiciones fueron muy dinámicas, pues se rompieron los típicos manejos del espacio que se enfocaban a las estructuras verticales $\mathrm{u}$ horizontales con justificaciones a la derecha o a la izquierda.

Los heraldos llegaban con una cara en blanco donde se imprimían datos sobre el sitio y la hora de proyección de las películas, el tratamiento de ese espacio impreso en Colombia se hacía con tipografía, así que el diseño que originalmente era propuesto por las diferentes productoras de cine era alterado con la información novedosa que, de acuerdo con la ciudad, el teatro y el día de proyección, se generaba. Se puede decir que no hubo un diseño gráfico que en Colombia formulara aportes a la gráfica contenida en los heraldos; por el contrario, los datos que se imprimían en el espacio en blanco rompían con el equilibrio de la pieza gráfica.

El propósito de los heraldos y de los carteles de cine era comercial, pero los heraldos eran más resistentes al paso del tiempo, lo cual los convirtió en objeto de colección De hecho hay más compilaciones de heraldos que de carteles, aunque en Colombia, las colecciones de los primeros son escasas: 
Luego de las primeras proyecciones de las películas, los exhibidores solían guardar los carteles comprados para usarlos en el futuro o simplemente se deshacían de ellos, lo que sucedió muy a menudo. Los carteles rentados debían ser devueltos junto con la película al distribuidor, quien los enviaba al siguiente cine, y la película pasaba gradualmente de cines de estreno a salas de segunda corrida. Eventualmente, los mejores conservados eran guardados (normalmente en bodegas) para la distribución de la película en el extranjero o para una posible nueva exhibición. (Agrasánchez, 1997, p. 8)

A diferencia de Colombia, en México, Estados Unidos y Espańa existían grupos de expertos en publicidad y diseño, contratados para la producción y creación de los heraldos y demás piezas promocionales que acompañaban las películas. Esta es una de las razones por las cuales los heraldos y las demás piezas no eran firmados.

En el caso de México, la época de oro del cine se dio en la década de los treinta. Sus producciones llegaron a otros países, como Colombia, logrando impactar al público, con lo cual, al igual que las películas de Hollywood, impusieron algunos estereotipos a partir de la imagen de diferentes actores y actrices como Sara García, llamada la madrecita del cine mexicano, Fernando Soler, Cantinflas y Jorge Negrete, entre otros.

Figura 14. Cartel de la película Abandonadas, con Dolores del Río

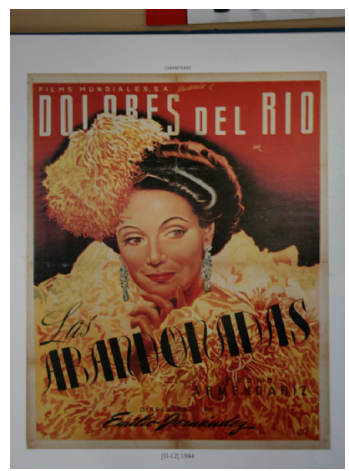

Fuente: Agrasánchez (1997) 


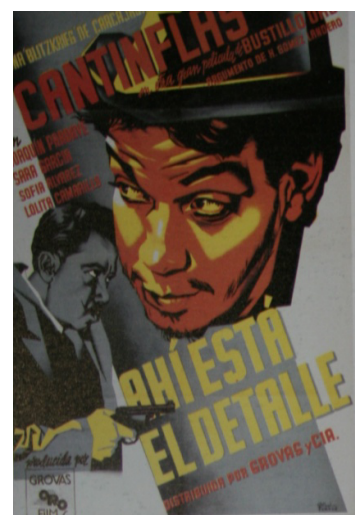

Fuente: Agrasánchez (1997)

En los años cuarenta, el cine mexicano se enfocó con más fuerza en los mercados latinoamericanos, gracias a las alianzas con Estados Unidos, convirtiéndose en el segundo productor, después de dicho país: “entre los países del hemisferio, México era considerado el Hollywood de habla hispana, marcando la pauta cultural e ideológica para Latinoamérica; como Estados Unidos en el resto del mundo" (Duque, Reyes, Greiff, Peters y Almanza, 2009, p. 15).

La promoción de películas mexicanas estuvo a cargo de Juan Antonio Vargas Ocampo, pionero de la publicidad de cine en México. En ese país, las agencias dedicadas a la promoción estaban muy bien organizadas: la división de trabajo incluía a periodistas, publicistas y dibujantes. Las piezas que cumplían con el propósito de la promoción, tales como los heraldos, incluían fragmentos del argumento o fotografías de las películas.

En Bogotá, al igual que en otras partes del país, donde el cine extranjero iba llegando, fue posible construir imágenes de ciudad a partir de las que se utilizaban en carteles y heraldos de productoras como Fox, la Metro-Goldwyn-Mayer, que tuvo sucursal en Bogotá, entre otras. Es interesante observar cómo una de las estrategias estuvo basada en el uso de imágenes con alto grado de reconocimiento, es decir, muy figurativas, 
donde lo más importante de la composición era la imagen de los protagonistas de la película.

Figura 16. Película Our Blushing Brides

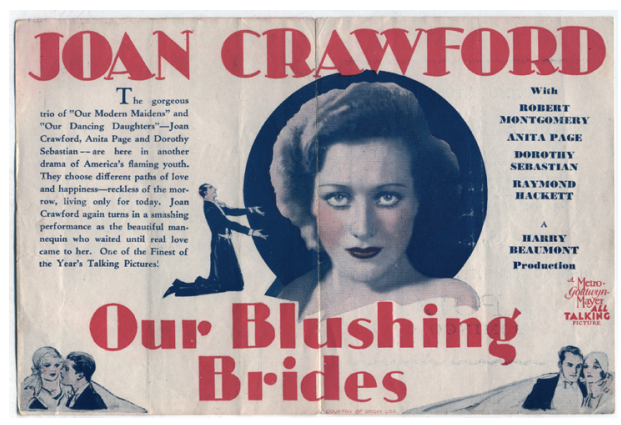

Fuente: Fundación Patrimonio Fílmico Colombiano

Figura 17. Película Our Blushing Brides

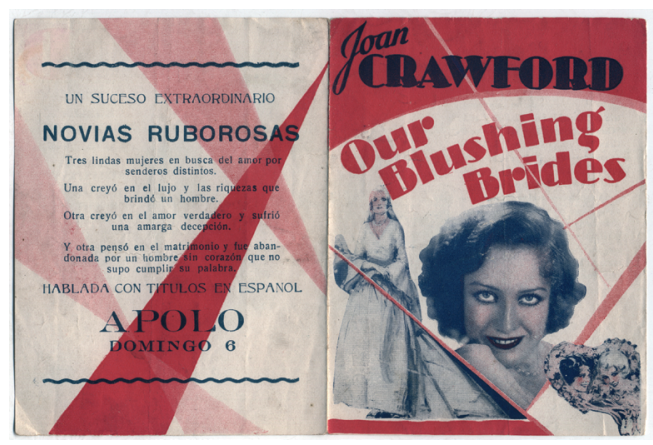

Fuente: Fundación Patrimonio Fílmico Colombiano

Las estrellas eran muy reconocidas, consolidaban el llamado Star-system con el cual el espectador se identificaba profundamente. Es decir, que así estas estrellas no pertenecieran a los contextos locales y no fueran reflejo de la situación política, económica, social y cultural de una ciudad latinoamericana, tal como ocurrió en Bogotá, cumplían la función de modelos. En otras palabras, dichas imágenes de 
los heraldos presentaban a unos protagonistas que, de cierta manera, idealizaban los roles femenino y masculino en torno a unas prácticas específicas, las cuales se evidenciaban en la forma de vestir, el maquillaje y el peinado, entre otros aspectos.

Como imagen recurrente de los heraldos, se observaba a una pareja de protagonistas sumergidos en la acción de una escena particular de la película, para lo cual se empleaban elementos gráficos como los colores fuertes y un manejo figurativo de la imagen, que reforzaba y exaltaba la personalidad de los actores.

En este sentido, esas imágenes de los heraldos, es decir, las producidas por el sistema de estrellas o Star-system, trabajaban como proyecciones de lo ideal para cualquier individuo; son imágenes que funcionaban muy bien, ya que expresaban situaciones o condiciones deseables.

En la publicidad cinematográfica, y en el caso concreto del programa de mano, se busca la ilusión para inducir un estado imaginario particular y para provocar la admiración más que la credibilidad, se invita al espectador a entrar en el mundo de ensoñación y fantasía que escenifica el séptimo arte. (GarcíaTalavera, 2002)

Dichos imaginarios responden y dependen de las condiciones sociales, económicas, políticas y culturales en las que se encuentren los individuos. Seguramente, el Starsystem tuvo gran impacto sobre la sociedad de la década de los años treinta y las posteriores, debido a la crisis económica que llevó a muchos a refugiarse y a buscar nuevas esperanzas e ideas de futuro en imágenes como las del cine que se observaban también en los heraldos.

Para esta consolidación de imaginarios, el Star-system desarrolló diversas estrategias, entre las cuales se encuentra el contrato y uso de ciertos actores y actrices como Greta Garbo, Marlene Dietrich, Gary Cooper y Clark Gable, ya que con ellos había más identificación por parte del público 5 .

5 Como parte de la biografía de estos actores y actrices, aparece información sobre la forma en que se hicieron famosos, hechos que en ocasiones son dramáticos, con lo cual, se elevaba el interés de los espectadores y 
Por otra parte, era frecuente que se elaboraran historias extraordinarias alrededor de todas estas estrellas, ya que el público que las seguía iba más allá de sus imágenes cinematográficas, pues coleccionaba todo lo relacionado con el actor o la actriz y se interesaba por su vida personal, supuestamente privada. Es por esto que, dentro del llamado Star-system, la publicación o circulación en distintos medios de biografías de las estrellas resultaba fundamental, como lo era el hecho de que en ellas se aludiera a acontecimientos dramáticos que daban cuenta del supuesto origen del actor o la actriz y de lo complejo que le resultó llegar a ser una gran estrella. Todo esto con el fin de que los espectadores que consumían las películas se sintieran más atraídos por sus ídolos y llegaran a un punto alto de identificación con ellos, hecho que después resaltó Andy Warhol en el movimiento pop de los años sesenta, cuando hacía referencia a los grandes personajes producto de la sociedad de consumo, para los cuales se creaba toda una vida que iba de lo real a lo irreal, y viceversa.

Lo más interesante es que dichos estereotipos surgían del contexto de las películas y eran trasladados a todos los objetos producidos dentro de la estrategia publicitaria que vendería las películas, como los heraldos, los carteles y las publicaciones periódicas, entre otros. Es el caso de la revista Estampa dedicada al entretenimiento y a diversos temas de la vida nacional, la cual tuvo gran acogida en diferentes sectores de la sociedad bogotana.

Al estudiar los contenidos de dicha publicación, se observa la materialización de ciertos imaginarios surgidos del cine, que tuvieron un gran impacto sobre las diferentes clases sociales en Bogotá.

Así, por ejemplo, en algunos avisos publicitarios de la revista se observa el traspaso de ciertos estereotipos cinematográficos a contextos diferentes, como los avisos de bebidas alcohólicas o de cigarrillos, evidenciando la influencia que sobre la sociedad

seguidores. Es el caso de Gable, quien, según algunas biografías, quedó huérfano de madre a los siete meses, posteriormente a los tres ańos de contraer matrimonio pierde a su esposa, Carole Lombard, en un accidente de aviación en el año de 1932; o el caso de Greta Garbo, hija menor de un barrendero y una asistente de hogar, cuyo padre falleció tempranamente, por lo cual, de acuerdo con algunas biografías, tuvo que trabajar desde muy temprana edad. 
Campos en Ciencias Sociales

Discursos visuales y sociedad

bogotana ejerció este medio masivo de comunicación, con lo cual se establecieron otras mentalidades frente a la realidad de la ciudad.

Figura 18. Anuncio publicitario de cigarrillos Lucky Strike

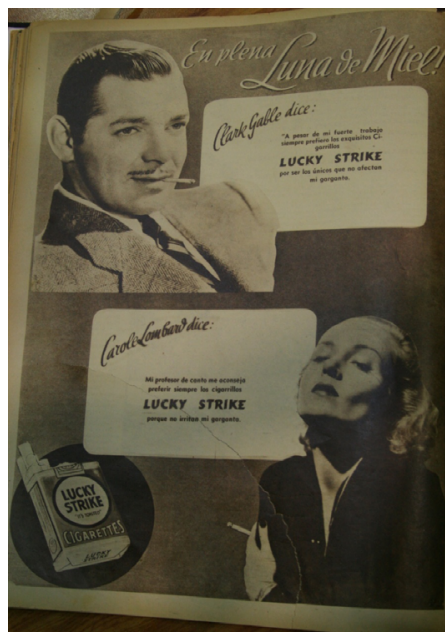

Fuente: revista Estampa, 1939, junio, pp. 36-37

Figura 19. Anuncio publicitario cigarrillos Virginia

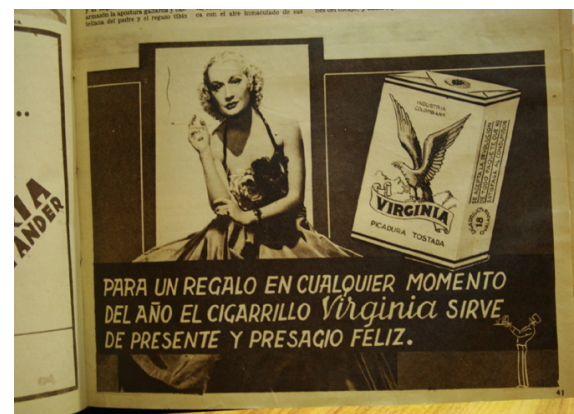

Fuente: revista Estampa, 13 de enero de 1940, p. 41 
Figura 20. Anuncio publicitario cigarrillos Lucky Strike

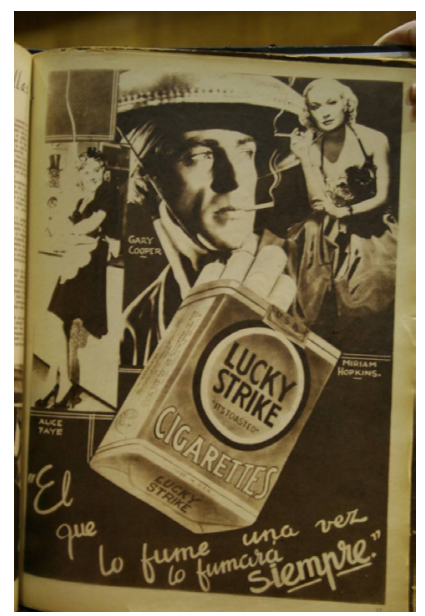

Fuente: revista Estampa, 10 de junio de 1939, p. 10

Figura 21. Anuncio publicitario cigarrillos Piel Roja

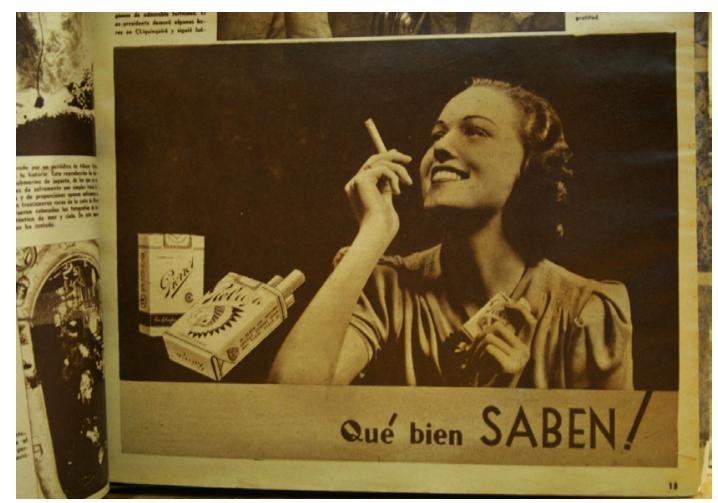

Fuente: revista Estampa, 10 de junio de 1939, p. 14 
Es importante saber cuáles fueron los estereotipos que se trasladaron a los ciudadanos y especialmente a las mujeres que veían las películas o que accedían a las publicaciones de la época.

Los estereotipos se hacen evidentes desde el título de la película, el cual, además de llamativo, fijaba nuevos roles que luego se trasladaban a las prácticas cotidianas de los ciudadanos bogotanos. Algunos de ellos son: La usurpadora, La señora casada necesita marido, Amor audaz, Santa, Llamadas de amor, Mi último amor, ¿Cuándo te suicidas?, La infiel, La cautivadora, donde la figura principal es femenina, y Los mosqueteros del monte blanco, Drácula, El impostor, El valiente, El ayudante del zar, Don Juan, El anónimo, donde el protagonista era un hombre. Otra evidencia de los estereotipos más utilizados eran los géneros trabajados, como la comedia, los charros y el folclor (en el caso mexicano), el misterio y la aventura, el drama social, los melodramas y los dramas amorosos:

El discurso fílmico, como todo discurso, se sitúa en una realidad sociohistórica que lo condiciona pero que, al mismo tiempo, es condicionada por él. Todo proceso significante, cualquiera sea la materia en la que se inscriba, es determinante de los otros discursos y, a su vez, determinado por ellos (y por las demás prácticas sociales). Se trata de un proceso de interacción generalizado que toma las formas de la intertextualidad, de la interdiscursividad y, aun, de la intersemioticidad. (Dalmasso, 2001)

La imagen de ciudad que se iba construyendo variaba entre los propios habitantes, ya que esta no solo se elaboraba a partir de narraciones e imágenes cinematográficas, sino que incluía experiencias personales y la imagen real de la ciudad, no idealizada, compuesta de situaciones poco agradables como la de pobreza de gran parte de los habitantes.

A pesar de que los imaginarios trasladados del cine norteamericano, del mexicano y del europeo corresponden a las realidades de sus países de origen, llegaban a materializarse en Bogotá en elementos como el lenguaje, la moda y los deseos de ciertos grupos sociales. 
Las películas norteamericanas, dentro del Star-system, trataban temáticas donde la imagen de la mujer estaba casi siempre supeditada a la imagen masculina; de este modo, el rol femenino fue siempre el débil y el masculino el fuerte, así que se consolidaban mentalidades machistas, que obviamente pasaban a la cultura colombiana. Sin embargo, hay un contraste interesante entre las imágenes de las mujeres en los carteles y los heraldos, donde son dependientes de la figura masculina; y las imágenes utilizadas en los avisos publicitarios, como los de los cigarrillos, donde la mujer y su imagen adquieren un carácter de misterio y de sofisticación, así mismo, en esos anuncios se muestra a una mujer más independiente de la figura masculina, aunque esté siendo utilizada como vehículo para vender ciertos productos ${ }^{6}$.

Aunque muchas veces se empleó la imagen de los actores y actrices para promocionar y vender algunos productos, el estereotipo de los actores del Star-system es el que termina imponiéndose, es decir, algunos productos no tuvieron la necesidad de hacer uso de la imagen de los actores y las actrices norteamericanos porque en su lugar aparecían modelos que tenían sus mismas características.

Esas características inciden en la creación de los imaginarios que surgieron de las películas y que, poco a poco, se fueron trasladando a diversos medios masivos de información con los cuales el público en general tenía contacto de forma cotidiana.

6 En el aviso de cigarrillos Virginia, se observa a Miriam Hopkins, actriz de Hollywood quien protagonizó varias películas como La venus de oro (1934), La feria de la vanidad (1935), Una chica rubia (1937), Una mujer para dos (1933), entre otras. En el aviso se ve a una mujer independiente, segura de sí misma, que no está supeditada a una figura masculina, signos que se evidencian en la mirada de la actriz, el vestido que lleva, la forma en que sostiene el cigarrillo, el cabello rubio y el maquillaje.

La pregunta que surge es: ¿por qué utilizar la imagen de una actriz norteamericana para promocionar una marca de cigarrillos en Colombia? Una de las respuestas puede ser que la imagen de los actores y actrices de cine hacía parte de todo un sistema de estrellas que no solo sirve para promocionar y vender una película, sino que podía ser un recurso para vender con efectividad cualquier producto.

En el segundo aviso nuevamente se recurre a la imagen de actores destacados como Miriam Hopkins, Gary Cooper y Alice Faye para vender cigarrillos Lucky Strike. En esta ocasión, las imágenes están ancladas a un texto que funciona como copy en el que se lee: "El que lo fume una vez lo fumará siempre". Con ese registro verbal anclado al registro visual, el público seguramente se identificaría con los actores y se proyectaría sobre sus imágenes; no se debe olvidar que las imágnes de estos actores fue construida por el Star-system para que se convirtieran en un ideal de hombre o de mujer. En comparación con el primer aviso, aquí la imagen de Hopkins pierde un poco de importancia porque está junto a la imagen de un hombre, que además es más grande que las demás, generando una especie de interdependencia entre las imágenes femeninas y masculinas. 
Dichos imaginarios también tienen como consecuencia la aparición de ciudadanos cada vez más diversos, con otras identidades culturales que no se basan en raíces propias sino en estereotipos y patrones extranjeros, y es esa hibridación de imágenes, experiencias, códigos y culturas la que va a construir la realidad urbana.

Las imágenes de los heraldos tienen claramente dos planos de interpretación: un plano de denotación donde, por lo general, se recurre a imágenes representativas, figurativas, representadas con medios fotográficos, con las cuales se alcanzaba un alto grado de identificación. Por otro lado, está el plano de la connotación, donde esas imágenes producen otros significados que hacen referencia a los roles y estereotipos.

Por supuesto, el heraldo maneja una estética que muestra lo bello y no lo feo, porque va ligado a procesos de mercadotecnia (marketing) o venta. "Está claro que las estrellas constituyen un intertexto estético que el público utiliza para derivar significado y placer de las películas" (Allen y Gomery, 1995, p. 223). Dicha idea de "estrella" hace parte de todo un mecanismo creado para promover una película. El actor dejaba de lado su identidad y pasaba a ser la estrella reconocida, de acuerdo con el papel y el rol que tuviese que desempeñar en una película.

Para estas estrellas se creaba toda una identidad donde su nombre, su aspecto físico, su vida, sus expresiones, la forma de actuar, sus prácticas y costumbres no correspondían a las del individuo real. Se ideaba todo un mundo de ficción, que luego sería consumido por el público.

Se puede afirmar que el cine como medio masivo de comunicación, hacía y hace parte de las estructuras ${ }^{7}$ sociales que dominan a los individuos, llegando incluso a producir en ellos otra mentalidad con relación a su realidad. Es en este aspecto donde

7 "Así la organización sobre la riqueza material, o sea la organización económica, vienen a ser las reales causas determinantes de las formas de pensamiento y de todos los sistemas sobre los que opera la conciencia: como el orden jurídico, las instituciones religiosas, la organización del estado, familia, las relaciones sociales, la misma producción de arte, los medios de comunicación, etc. De acuerdo con ello la ideología actúa en la superestructura, correspondiendo a la infraestructura y el área económica considerada globalmente” (Silva, 1978, p. 73). 
los niveles de significado del mensaje pueden ser complejos, generalmente afectados por tendencias políticas, económicas, sociales y culturales:

La función ideológica global de la estrella de cine es ayudar a preservar el statu quo y por tanto el poder de la ideología dominante. La imagen de la estrella representa para Dyer una tentativa de encauzar, encubrir o desplazar algunas de las contradicciones inherentes a la ideología dominante; hace que los problemas fundamentales dejen de parecer problemáticos, apacigua las posibles amenazas a la ideología dominante y hace que las cuestiones relativas a las clases sociales parezcan personales. (Allen y Gomery, 1995, p. 224)

Detrás de la imagen de ciudad están las narraciones construidas por la mercadotecnia, a través del uso de imágenes fijas o móviles que nos permiten proyectar ciertos deseos sobre algunos contextos urbanos, para lo cual se recurre frecuentemente a la retórica y a la poética de la imagen, con metáforas, hipérboles, aliteraciones, símiles y demás figuras retóricas.

Estas estrategias apelan a todos los sentidos, llegando incluso a alterar nuestra percepción sobre el lugar. Hay ciudades que, a partir de estas imágenes, se consolidan como ciudades acontecimiento: "a través de las cuales todos pueden acceder al mundo de los medios y de la visibilidad" (Silva, 1978, p. 296). Este es el caso de Hollywood, concebida como ciudad espectáculo gracias a todo este imaginario del sistema de estrellas (Star-system). Con una estrategia definida "de la apariencia se tiende a crear una ciudad imaginaria que preceda, esté por encima y se adhiera a la ciudad real y material" (Amendola, 2000, p. 299).

La construcción de imagen de ciudad a través de los estereotipos vendidos por el cine lleva a la búsqueda de placer y belleza, generando escenarios hiperestéticos (los cuales son evidentes hasta nuestros días: el imitar a un actor o actriz, su aspecto físico, sus peinados, vestidos, actitudes, etc.) que dan como resultado "un escenario metropolitano impregnado de un esteticismo difundido basado en los deseos, en las sensaciones y en la inmediatez" (Amendola, 2000, p. 149), creando así imágenes de ciudad, a partir de personajes salidos de las pantallas de cine que se encarnan en 
algunos habitantes de la ciudad, y que son personificaciones ${ }^{8}$ de ideales de hombres y mujeres impuestas por el cine.

Al permitir que la construcción de la imagen de la ciudad se concentre en estrategias de mercadotecnia, elaboradas por profesionales de la publicidad y el diseńo, que además no son nacionales, se cae en el riesgo de que las particularidades de la ciudad desaparezcan, como sucedió en la Bogotá de aquellos ańos: una ciudad que trataba de imitar a otras ciudades y que poco a poco se identificaba cada vez más con otros contextos.

Las imágenes de los heraldos, en apariencia, se presentaban como obvias; sin embargo, proyectaron contenidos que afectaron a los receptores, no necesariamente en términos de subvertir un mensaje y una interpretación, pero sí con una significación profunda, asociada a sistemas políticos, económicos y socioculturales. En estas piezas gráficas, se evidencia el impacto y la influencia de estéticas extranjeras, especialmente norteamericanas y europeas.

Al igual que el cartel de cine, la estética utilizada en el heraldo plantea una función muy interesante, presentada por Coronado (2001), por medio de la metáfora del espejo:

Mientras que en pintura el referente de la imagen es el propio mundo, en el cartel, el referente de la imagen será el espectador. Entre ambos -imagen y espectador- será necesario mantener una relación de identificación mutua para que el proceso persuasivo característico del sistema de la publicidad llegue a desarrollarse, y en este proceso, para el espectador ninguna estrategia garantiza con mayor seguridad una vinculación de atracción y de deseo frente a su imagen, como la "estrategia del espejo". (p. 32)

En los heraldos de cine, hay elementos que llevan a varios niveles de interpretación, como lo menciona Barthes: el trucaje, donde a través de la superposición de imágenes

8 "Cuando hablamos de personajes, no solo nos referimos a la gente notable de carne y hueso, sino también a seres mediáticos, ficticios o a aquellos constituidos por románticas reminiscencias” (Silva, 2004). 
que pertenecen a una totalidad, se genera una narración a partir de las escenas más destacadas de una película; dichas imágenes conservan un nivel de iconicidad muy alto, aunque son fragmentos que provienen de otro medio (película de cine).

En el caso de las figuras 22 y 23, una de las actrices más conocidas en Hollywood aparece haciendo parte del eje central de la composición del heraldo, Greta Garbo, quien se convierte en uno de los modelos y estereotipos más usados por el sistema de estrellas o Star-system: su mirada emite una fuerza permanente y directa sobre el observador. A los dos lados de la imagen principal se observan fragmentos de la película que se está promocionando, The kiss, dichos elementos constituyen el registro visual del heraldo; por otro lado, están los textos que conforman el registro verbal.

Figura 22. Película Lo Eterno

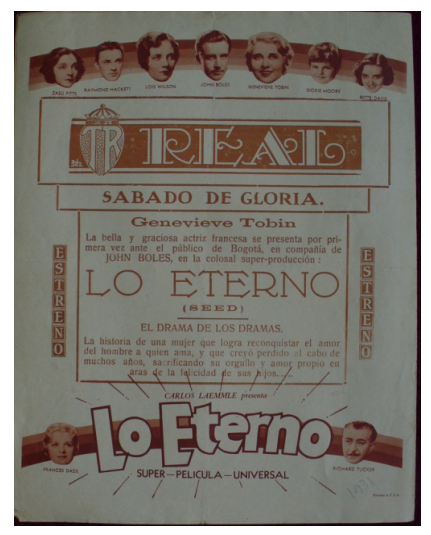

Fuente: Fundación Patrimonio Fílmico Colombiano, 1931 


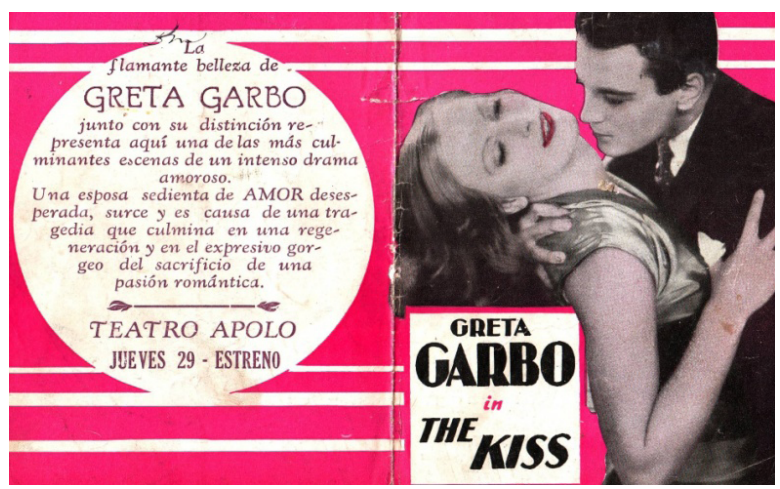

Fuente: Fundación Patrimonio Fílmico Colombiano

En ambos casos (registros visual y verbal) la imagen produce diferentes sentidos, para lo cual recurre a códigos como los retóricos; en este caso a las metáforas visuales que son, finalmente, las que producen sentidos profundos y llevan al observador a tener interpretaciones como, por ejemplo, la idea de mujer respecto a sí misma, los demás o a su contexto.

En el nivel de los significantes, se observa que hay montajes que funcionan como fragmentos de realidad, que le permiten al observador tener una idea de lo que es la película. Por otra parte, la pose es muy importante, la mirada fija, desafiante, que hace que el observador se sienta incluso intimidado.

En el segmento lateral izquierdo, se observa a los dos personajes principales en una de las actitudes más comunes del sistema de estrellas (Star-system): el de la mujer sometida a la figura masculina, al lado derecho se ve otro de los personajes que refuerza un rol masculino dominante.

Estéticamente, los códigos retóricos aquí presentes exaltan y mitifican al personaje central (Greta Garbo), que además tiene un maquillaje, una mirada, un peinado y una actitud que llevan a la construcción de ciertos estereotipos, los cuales, finalmente, ejercerán gran influencia sobre los observadores, intérpretes o receptores. Por otro 
lado, está el mensaje lingüístico que, dentro de su función de anclaje, refuerza la imagen que aparece en los heraldos.

Como se ha visto, el recurso más utilizado en los heraldos de cine es el de la imagen fotográfica, que tiene gran impacto y altos niveles de iconicidad y de identificación con el receptor. Algunos medios conciben la fotografía como testimonio de autenticidad, lo cual se observa en el concepto del sistema de estrellas o Star-system, y el manejo que se hace de los personajes en los heraldos; es el realismo, el elemento con el que se va a convencer y a seducir a un público específico.

El observador de las fotografías, el consumidor, se conecta con cierta aura que las fotografías tienen, la cual lo lleva a proyectarse sobre dichas imágenes y los personajes que, aunque muchas veces anónimos, ejercen gran impacto en el receptor o intérprete.

En el caso de la figura femenina, se observa cómo la imagen fotográfica advierte algunas convenciones, de carácter simbólico, cuando se observan posturas y gestos específicos, o convenciones de género, relativas a cada época, aunque muchas veces estos códigos "lo que recogen no es tanto la realidad social cuanto las ilusiones sociales, no tanto la vida corriente cuanto una representación especial de ella” (Burke, 2005. p. 32).

Por lo tanto, aunque la imagen fotográfica puede ser considerada como espejo de un momento, este espejo puede ser manipulado con la construcción de algunos estereotipos producidos por la sociedad de consumo. Sin embargo, según Peter Burke (2005), la imagen refleja contenidos más profundos como, por ejemplo, la mentalidad de una época.

Es por esto que las relaciones entre la imagen y su significado implican la existencia de un intérprete activo, y aunque muchas veces se ha considerado que la imagen publicitaria es obvia, tiene un sentido oculto muy fuerte dada su construcción a partir de códigos retóricos: "estas artes "imitativas" conllevan dos mensajes: un mensaje denotado que es el propio análogo, y un mensaje connotado que es, en cierta manera, el modo en que la sociedad ofrece al lector su opinión sobre aquel" (Barthes, 1982, p. 13). 
Un aspecto importante de este fenómeno es la forma en que, a través de las imágenes que llegaron a Bogotá por medio de los heraldos, fueron trasladados dichos estereotipos, no solamente por ser una tendencia de la moda, sino por una serie de imaginarios construidos desde una estética aplicada en una estrategia publicitaria que tuvo como principal vehículo la imagen impresa. Las películas y las imágenes producidas para su promoción "son mitos, representaciones de cosas perdidas y cosas deseadas” (Allen y Gomery, 1995, p. 211).

Es precisamente la configuración formal que tienen dichas representaciones en los heraldos, la que permite hablar de un doble nivel de significación. Uno referido a lo que está presente en las imágenes fotográficas: la forma, el color, la disposición de elementos, los textos, el formato, etc. Otro que se refiere a la interpretación profunda de cada uno de los símbolos allí presentes cargados de roles y estereotipos. Además, estas interpretaciones están afectadas e influenciadas por intereses políticos, económicos, sociales y culturales extranjeros.

Por lo tanto, ¿en qué medida se puede decir que las películas y las imágenes, que fueron utilizadas en los heraldos, son artefactos culturales, políticos y económicos?

Dentro de estos niveles de lo llamado obtuso, se puede encontrar la respuesta, ya que sí son artefactos utilizados en un momento específico, manipulados a partir de los registros verbales y visuales de la imagen que, además, manifiestan una ideología dominante.

El sentido oculto de las imágenes que aparecen en los heraldos incluye la producción de un registro imaginario, relacionado con la psique del espectador, donde se ubica el poder de seducción de los personajes que aparecían en los heraldos y que surgían de las películas, por lo cual dichas imágenes se convirtieron en objetos de deseo. Pero, ¿cómo se generó este nivel de identificación? A través de la forma en que el objeto de consumo (imágenes de actores y actrices) se presentaba al receptor. Además, la relación entre texto e imagen era tan fuerte que entre ambas se generó un anclaje, el cual reforzaba la información. 
Todo este fenómeno del sistema de estrellas o Star-system, se proyectó en Colombia, como se mencionó, con el uso de las imágenes de las principales estrellas de las películas que ingresaron a otros espacios, como las publicaciones periódicas y los avisos publicitarios de algunos productos. Este hecho generó poco a poco identificación, en un nivel profundo, entre las imágenes y los consumidores o receptores, a tal punto que se fue generando una estética visual donde la gente pudiente y no pudiente de zonas urbanas, imitaba a los actores en la forma de vestir, peinarse y maquillarse, hasta la afirmación de ciertos roles y comportamientos como los desarrollados por las mujeres, que, en algunos casos, se presentaban un poco liberadas para su época, pero en otros, sometidas y sumisas a figuras masculinas.

Finalmente, se puede concluir que el contenido de las imágenes construidas para los heraldos de cine, que llegaron promocionando películas norteamericanas a Colombia en la década de los treinta siendo piezas publicitarias, no solo tenían un significado obvio, sino que tenían un sentido profundo que se daba a partir de diversas variables, como el contexto histórico en el que fueron elaboradas. Por lo cual, no solo tuvieron una función publicitaria, sino que además ejercieron una función política, económica y cultural que determinó los patrones culturales de las sociedades en las que se produjeron y de las sociedades a las cuales llegaron, estas últimas sufriendo cambios en su identidad 


\section{Referencias}

Allen, R., y Gomery, D. (1995). Teoría y práctica de la historia del cine. Barcelona: Barcelona: Paidós Ibérica.

Agrasánchez, R. (1997). Carteles de la época de oro del cine mexicano. México: Editorial México: Archivo Fílmico Universidad de Guadalajara.

Barthes, R. (1982). Lo obvio y lo obtuso. Imágenes, gestos, voces. Barcelona: Ediciones Paidós.

Barthes, R. (1999). Mitologías. Madrid: Siglo Veintiuno Editores.

Burke, P. (2005). Visto y no visto. El uso de la imagen como documento histórico. Barcelona: Crítica, Barcelona.

Coronado, D. (2001). La metáfora del espejo: teoría e historia del cartel publicitario. Sevilla: Alfar.

Dalmasso, M. T. (2001). Discurso fílmico y construcción de las identidades: figuras de mujer. Revista Latina de Comunicación social, 4(44).

Duque, P., Reyes, C., Greiff, B., Peters, V., y Almanza, D. (2009). Cartel ilustrado en Colombia: década 1930-1940. Colombia: Editorial Universidad Jorge Tadeo Lozano.

García-Talavera, J. F. (2002). Aspectos socioculturales del programa de mano de MetroGoldwyn-Mayer: la cinefilia. Revista Latina de Comunicación Social, 5(47). Mora, C. I., y Carrillo, A. (2003). Hechos colombianos para ojos y oídos de las Américas. Bogotá: Ministerio de Cultura.

Silva, R. (2005). República liberal, intelectuales y cultura popular. Medellín: La Carreta Editores.

Silva, A. (1978). La comunicación visual: como teoría y método para la lectura de las artes y sistemas visuales. Bogotá: Ediciones Suramérica. 
Silva, A. (2004). Bogotá imaginada. Bogotá: Alfaguara.

Wirth, L. (2005). El urbanismo como modo de vida. Bifurcaciones, (2), 1-15. Recuperado de www.bifurcaciones.cl/002/reserva.htm 